\title{
AVIAÇÃO AGRÍCOLA: LIGAÇÃO ENTRE REGULAMENTAÇÃo AERONÁUTICA E AGRÍCOLA
}

Rafael Medeiros Hespanhol

Bacharel em Administração pela UNESP e Piloto Comercial de Avião em Presidente Prudente, SP. E-mail: voehes@gmail.com

\section{RESUMO}

Tanto a aviação quanto a agricultura possuem características próprias de suas atividades. Uma vez que não existe nenhuma recomendação ou obrigação estabelecida pela Organização da Aviação Civil Internacional $(\mathrm{OACl})$, este artigo mostra algumas das características compartilhadas pelas atividades da aviação agrícola no que diz respeito à legislação e regulamentação no Brasil, realizada principalmente pelo Ministério da Agricultura, Pecuária e Abastecimento (MAPA) e pela Agência Nacional de Aviação Civil (ANAC).

Palavras-chave: Aviação Agrícola; Frota de Aeronaves; Agricultura; OACl; Regulamentação Aeronáutica.

\section{INTRODUÇÃO E OBJETIVO}

O presente artigo busca contextualizar a aviação agrícola brasileira no que diz respeito aos órgãos e leis que a regem e ao mercado em que se situa. Diferente de outras áreas da aviação, esse segmento específico oferece um Serviço Aéreo Especializado e necessita de legislação e atenção específica. No entanto, o Sindicato Nacional das Empresas Agrícolas alega que há excesso de regulamentação entre o Ministério da Agricultura, Pecuária e Abastecimento (MAPA) e da Agência Nacional de Aviação Civil (ANAC), uma vez que a Organização da Aviação Civil Internacional $(\mathrm{OACl})$, da qual o Brasil faz parte, não considera Serviços Aéreo Especiais (como a aviação agrícola) em seus padrões e práticas recomendadas.

Busca-se compreender porque o governo brasileiro entende que a aviação agrícola deve ser fiscalizada pelo MAPA em conjunto com a ANAC. O que motiva o assunto é o momento em que a $\mathrm{OACl}$ e a Comissão Latino Americana de Aviação Civil (CLAC) discutem propostas de um Regulamento Aeronáutico Latino-americano que inclua regras para operações aeroagrícolas de pulverização no início de agosto de 2013 e que pode dar novos rumos à regulamentação do setor no país.

\section{MÉTODOS}

Para este artigo, foi realizado levantamento bibliográfico de caráter qualitativo em livros, leis e trabalhos científicos que abordassem economia, modernização na agricultura, definições 
aeronáuticas e características da agricultura no Brasil; e levantamento de dados de caráter quantitativo através de pesquisas a bancos de dados do governo e órgãos ligados à aviação e agricultura. Este levantamento bibliográfico permitiu uma breve análise da aviação agrícola no Brasil.

Cervo e Bervian (2002, p. 69) definem que o estudo exploratório auxilia o surgimento de hipóteses significativas para uma possível transformação em pesquisa em um segundo momento. Eles explicam ainda que tais estudos têm por objetivo a familiarização com o assunto estudado e descoberta de novas ideias.

Assim, os conhecimentos teóricos unidos à exploração dos dados obtidos junto a órgão governamentais foram as ferramentas que permitiram maximizar a análise para chegar a algumas conclusões.

\section{RESULTADOS}

Segundo a Portaria №190/GC-5, de 20 de março de 2001 do Comando da Aeronáutica, Serviço Aéreo Especializado (SAE) é toda atividade aérea distinta de transporte aéreo público. Esta portaria ainda cita as atividades definidas como serviço aéreo especializado e as particularidades de cada uma delas.

A aviação agrícola é definida como um SAE, outras atividades de SAE que podemos citar como exemplo são o Aerolevantamento, Aerodemonstração, Aeropublicidade, Apoio Aéreo, Aeroreportagem, Aeroinspeção, Aerofotografia, Aerocinematografia e Combate a Incêndios.

Este artigo focará no SAE Aeroagrícola, definido nesta mesma portaria pelo Comando da Aeronáutica como:

“(...) atividade aérea com a finalidade de proteger ou fomentar o desenvolvimento da agricultura em quaisquer de seus aspectos, mediante o uso de fertilizantes, semeadura, combate a pragas e a vetores propagadores de doenças, aplicação de herbicidas, desfolhadores e povoamento de águas." (Portaria 2001)

O Código Brasileiro de Aeronáutica (1986) regula que este tipo de serviço deverá obedecer a regulamento especial. O regulamento especial por parte da Agência Nacional de Aviação Civil é o Regulamento Brasileiro de Aviação Civil (RBAC) № 137, de 2012, que tem como título “Certificação e Requisitos Operacionais: Operações Aeroagrícolas".

O Decreto № 86.765, de 22 de dezembro de 1981 em seu artigo 10 cita além do órgão aeronáutico, o Ministério da Agricultura como também responsável pela aviação agrícola: 
Art. 1․ Compete ao Ministério da Agricultura propor a política para o emprego da aviação agrícola, visando à coordenação, orientação, supervisão e fiscalização de suas atividades, de acordo com as normas previstas neste regulamento.

O artigo 4ำ do mesmo decreto descreve a competência do MAPA em relação à aviação agrícola.

Art. 40. Ao Ministério da Agricultura compete: I - estudar e propor diretrizes para a política nacional de aviação agrícola; II - registrar e manter o cadastro de empresas que, sob qualquer forma, incluam a exploração da aviação agrícola entre seus objetivos ou a realizem em consonância com os interesses da sua exploração agropecuária;

III - manter registro estatístico da pesquisa tecnológica e econômica e outras necessárias, relativas à utilização da aviação agrícola;

IV - homologar e fazer publicar a relação dos produtos químicos em condições de serem aplicados pela aviação agrícola, atendidas as normas de proteção biológica, de proteção à saúde e as restrições de análise toxicológica do produto, realizada pelo Ministério da Saúde;

$\mathrm{V}$ - realizar testes operacionais de aeronaves e ensaios de equipamentos quanto aos seus desempenhos como máquinas de aplicação aérea em trabalhos agrícolas, propondo ao Ministério da Aeronáutica o atestado liberatório da aeronave equipada, abrangendo: - aeronaves e equipamentos já em uso no território nacional; - aeronaves requeridas para a importação; e - aeronaves de fabricação nacional.

VI - participar das decisões sobre concessão de incentivos fiscais e favores creditícios oficiais em benefício de empresas que utilizem ou explorem aviação agrícola, juntamente com os demais órgãos especializados na matéria, promovendo entendimentos com órgãos públicos afins e Banco Central do Brasil, visando o estabelecimento da política creditícia e de incentivos para a atividade;

VII - fiscalizar as atividades da aviação agrícola no concernente à observância das normas de proteção à vida e à saúde, do ponto-de-vista operacional e das populações interessadas, bem como das de proteção à fauna e à flora, articulando-se com os órgãos ou autoridades competentes para aplicação de sanções, quando for o caso;

VIII - dar orientação técnica e econômica à exploração dessa atividade; IX - estabelecer padrões técnico-operacionais de segurança de tripulantes e normas de proteção às pessoas e bens, objetivando a redução de riscos oriundos do emprego de produtos de defesa agropecuária;

$X$ - dar apoio às pesquisas e às operações de aviação agrícola realizadas por Universidades e Escolas superiores do País e empresas de pesquisa;

$\mathrm{XI}$ - promover a publicação periódica e atualizada de leis, regulamentos e outras matérias que interessem, especificamente, à aviação agrícola, ouvido o Ministério da Aeronáutica quanto aos aspectos técnicos pertinentes;

XII - conciliar a missão pioneira do poder público em relação a pesquisas, treinamento de pessoal e demonstração de equipamento e técnicas, com o 
princípio de que cabe à iniciativa privada operar e desenvolver essas atividades de aviação agrícola;

XIII - baixar normas sobre demonstração de aviação agrícola com equipamentos de aspersão e pulverização.

O MAPA fica responsável também pela emissão de registros das empresas e pilotos de aviação agrícola. Este Ministério também define as restrições que devem ser seguidas pelo aviador na aplicação de agrotóxicos, tais como: a distância mínima necessária entre aplicações e: povoações; cidades; vilas; bairros; ou áreas de mananciais de captação de água para abastecimento.

\section{DISCUSSÃO}

Para se ter uma ideia da concentração de aeronaves agrícolas por região, podemos realizar uma busca no Registro Aeronáutico Brasileiro (RAB). Contudo, antes disso é importante sabermos que os dados do RAB levam em conta o endereço do operador da aeronave, e não necessariamente o aeródromo onde a mesma esteja porventura operando.

No caso de um Serviço Aéreo Especializado (SAE), o Código Brasileiro de Aeronáutica (CBA, 1986) define "operador" como a pessoa jurídica que tem autorização de serviços especializados; o proprietário da aeronave ou quem a use diretamente ou através de seus prepostos (quando se tratar de serviços aéreos privados); o fretador que reservou a condução técnica da aeronave, a direção e a autoridade sobre a tripulação; o arrendatário que adquiriu a condução técnica da aeronave arrendada e a autoridade sobre a tripulação.

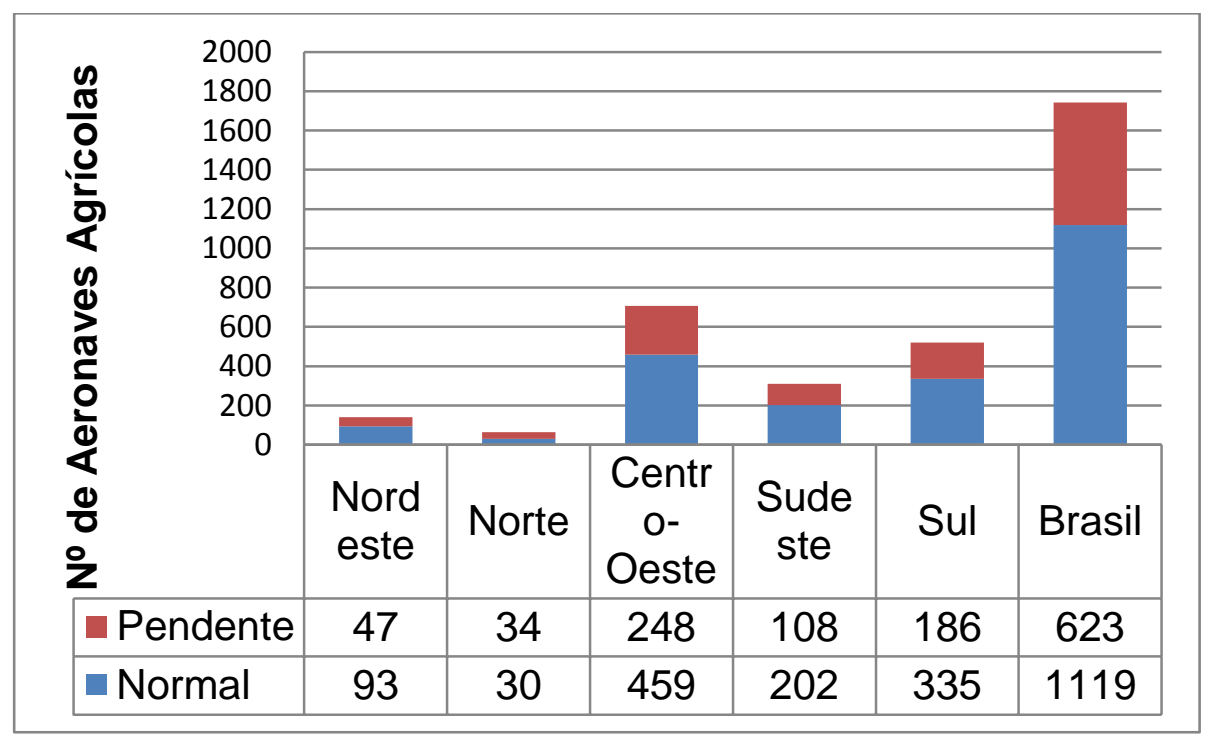

Figura 1. № de Aeronaves Agrícolas por Região

Fonte: RAB (2012) 
Analisando os dados do RAB (2012), vemos que o Brasil possui o total de 1.742 aeronaves agrícolas. A maior parte dessas aeronaves se encontra registrada no Centro-Oeste brasileiro, seguido pelo Sul do país, como podemos notar também quando analisamos a porcentagem de cada região:

Quadro 1. Porcentagem de aeronaves agrícolas por região

\begin{tabular}{|c|c|c|c|c|c|}
\hline Região & Nordeste & Norte & Centro-Oeste & Sudeste & Sul \\
\hline $\begin{array}{l}\text { Quantidade de Aeronaves } \\
\text { Agrícolas }\end{array}$ & $8,04 \%$ & $3,67 \%$ & $40,59 \%$ & $17,80 \%$ & $29,91 \%$ \\
\hline
\end{tabular}

Tal informação é interessante, pois evidencia tratar-se realmente de um segmento de mercado que merece ser analisado separado de outras áreas da aviação, uma vez que a aviação agrícola está ligada diretamente à agricultura e à tecnologia empregada na agricultura.

Para se ter noção de quão específica é a aviação agrícola, ao analisarmos a frota total de aviões no Brasil (incluindo aeronaves agrícolas) no mesmo período, encontramos uma situação totalmente diferente, mostrando que quase metade de toda a frota de aeronaves brasileiras se encontra no sudeste do país.

Quadro 2. Porcentagem de aeronaves por região

\begin{tabular}{|l|c|c|c|c|c|}
\hline & Nordeste & Norte & $\begin{array}{c}\text { Centro- } \\
\text { Oeste }\end{array}$ & Sudeste & Sul \\
\hline Quantidade total de aeronaves & $8,93 \%$ & $9,55 \%$ & $18,89 \%$ & $46,40 \%$ & $16,23 \%$ \\
\hline & Fonte: RAB $(2012)$ & &
\end{tabular}

Gallo estabelece dependência não apenas da aviação agrícola em relação à agricultura brasileira, mas também da necessidade da aviação agrícola pela agricultura nas propriedades de grande extensão. (2006, p. 68)

(...) a crescente utilização de aeronaves para aplicação de defensivos agrícolas nas lavouras se configura como um elemento sugestivo da incorporação, cada vez maior, de modernizações na agricultura brasileira. Este tipo de uso e sua inserção no circuito espacial produtivo passam a ser correntes. Como o circuito espacial da produção de soja se espalha por todo o território nacional, na arena de produção propriamente dita, isto é, nas grandes fazendas da região Centro-Oeste, a aviação se insere na pulverização (com defensivos agrícolas) de lavouras; nessas fazendas a 
aviação agrícola se faz necessária dada a grande extensão das propriedades.

Com relação ao grande número de aeronaves no Centro-Oeste, Santos e Silveira (2001) mostram muito bem o fluxo de empresas de aviação agrícola migrando da região Sul para a região Centro-Oeste do país ao longo das décadas de 1970, 1980 e 1990. Eles consideram que a utilização de métodos como a aviação agrícola são evidência da moderna agricultura que já vinha se desenvolvendo na região.

Silveira (2004) estabelece que os cultivos que mais utilizam a aviação agrícola são o arroz (sequeiro e irrigado), a soja, a banana, o algodão (herbáceo), o trigo, o milho, o feijão, a laranja e a cana-de-açúcar. Ele ressalta ainda que dentre estas o feijão e a laranja tem baixa utilização de aviação agrícola.

Nos dados do IBGE, temos que o arroz, o milho e a soja (principais utilizadores de aviação agrícola) somam quase $93 \%$ do total da produção agrícola levantada. Com isso, podemos comparar a porcentagem da frota de aeronaves agrícolas por região e a proporção do volume de produção agrícola das mesmas regiões.

Quando analisamos os dados de estimativa da safra nacional de cereais, leguminosas e oleaginosas do IBGE para Junho de 2013, podemos confirmar relação existente entre o número de aeronaves agrícolas por região e as áreas plantadas, conforme demonstrado nos gráficos a seguir.

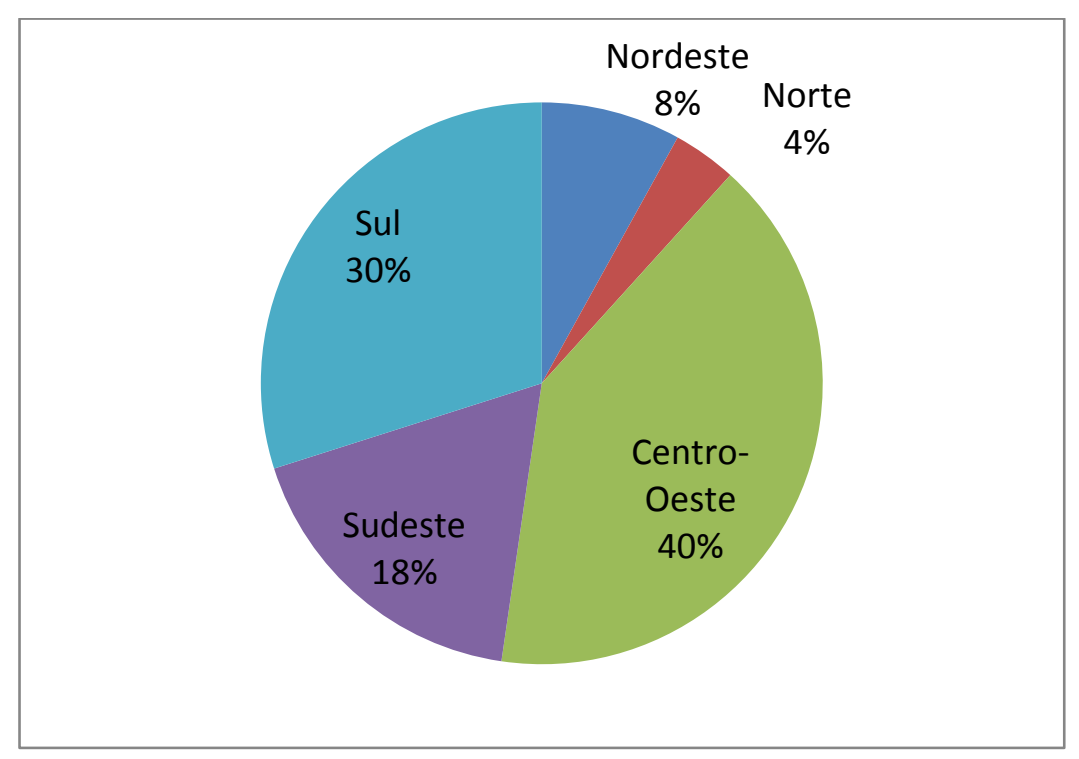

Figura 2. Aeronaves Agrícolas por Região do Brasil

Fonte: RAB (2012) 


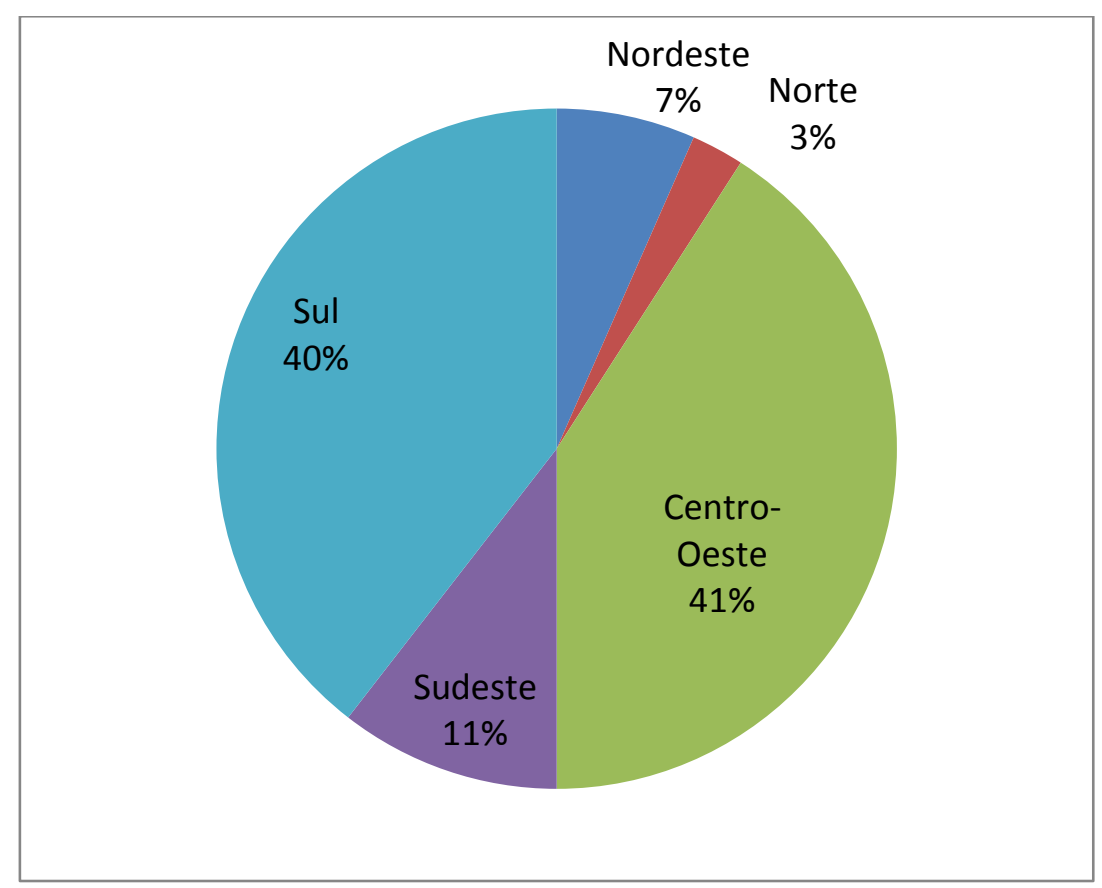

Figura 3. Volume de Produção Agrícola por Região do Brasil (ton)

Fonte: IBGE (2013)

\section{CONCLUSÃO}

Quando notamos diferenças entre a aviação geral e um serviço aéreo especializado, fica evidente que se trata de um mercado específico, que merece ser regulado e fiscalizado com normas e diretrizes próprias da atividade que executa.

A aviação agrícola tem pouquíssima relação com a aviação geral, desde sua regulamentação até a distribuição de sua frota que, conforme indicam os dados levantados, está ligada diretamente à agricultura.

O Brasil é integrante da $\mathrm{OACl}$ e por esse motivo, está sujeito às suas normas conforme estabelecido no $\mathrm{CBA}$. Uma vez que a $\mathrm{OACl}$ determina que regulamentos relacionados à aviação agrícola fiquem a cargo de cada país, o Brasil fiscaliza e regulamenta a aviação agrícola nacional principalmente através do MAPA e da ANAC, o que tem gerado descontentamento por parte do SINDAG que alega existir número muito grande de regulamentos a serem seguidos e pede que haja uma ação do governo e entidades ligadas ao setor para que ocorra a desburocratização exagerada do setor e seja eliminada a multiplicidade e superposição de regulamentações e fiscalizações.

A CLAC inicia uma discussão para estabelecer regras e padrões através do compartilhamento de situações e conhecimentos entre os países da América Latina, o que pode, em alguns anos, mudar a atual regulamentação do setor no Brasil. 


\section{REFERÊNCIAS}

AGENCIA NACIONAL DE AVIAÇÃO CIVIL. RBAC n. 137: Certificação e Requisitos Operacionais: Operações Aeroagrícolas. Brasil, 2012. 247 p

ANAC - Agência Nacional de Aviação Civil. Disponível em: http://www.anac.gov.br. Acesso em: 02 de ago. 2013.

CBA - Código Brasileiro de Aeronáutica - Lei no 7.565 de 19 de dezembro de 1986.

CERVO, A.L.; BERVIAN, P.A. Metodologia Científica. 5ạ edição. São Paulo: Prentice Hill, 2002.

GALLO, F. O papel do transporte aéreo na integração do território brasileiro. Dissertação de Mestrado. Instituto de Geociências, Universidade Estadual de Campinas, Campinas/SP, 2006.

IBGE - Instituto Brasileiro de Geografia e Estatística. Disponível em: http://www.ibge.gov.br. Acesso em 02 de ago. 2013.

ICAO - International Civil Aviation Organization - ANNEX 6 Part II - Internacional General Aviation - Aeroplanes. Seventh Edition. July 2008. Montreal, Canada.

MAPA - Ministério da Agricultura, Pecuária e Abastecimento. Disponível em: http://www.agricultura.gov.br. Acesso em: 08 de ago. 2013.

RAB. Registro Aeronáutico Brasileiro. Rio de Janeiro: ANAC, 2013.

SANTOS, M.; SILVEIRA, M. L. O Brasil. Território e sociedade no início do século XXI. 2ed. Rio de Janeiro: Record, 2001.

SILVEIRA, Vinicius Roberto. Cenário atual da aviação agrícola no Brasil. 2004. 184 f. Tese de mestrado - Instituto Tecnológico de Aeronáutica, São José dos Campos.

SINDAG - Sindicato Nacional das Empresas de Aviação Agrícola. Disponível em: http://www.sindag.com.br. Acesso em 02 de ago. 2013.

SRVSOP - Sistema Regional de Cooperación para la Vigilancia de la Seguridad. Disponível em: Operacional http://www1.lima.icao.int/srvsop. Acesso em 02 de ago. 2013. 